\title{
LOS MODELOS Y EL PAPEL DE LAS MUJERES EN LA COMEDIA ILUSTRADA. UN CASO PRÁCTICO DE SU ENSEÑANZA Y ANÁLISIS EN LAS AULAS UNIVERSITARIAS DESDE EL ENFOQUE DE GÉNERO.
}

\author{
MODELS AND THE ROLE OF WOMEN IN ILLUSTRATED COMEDY. \\ A PRACTICAL CASE OF ITS TEACHING AND ANALYSIS IN \\ UNIVERSITY CLASSROOMS FROM A GENDER PERSPECTIVE.
}

Maribel Martínez López. Universidad de La Rioja - España

maribel.martinez@unirioja.es

Resumen: El artículo presenta el estudio de los motivos temáticos ilustrados y las características estéticas de la comedia neoclásica de buenas costumbres aplicados a la obra $L a$ familia a la moda, de Ma Rosa de Gálvez, tal y como se desarrolla su análisis en el aula dentro de una asignatura del Grado en Lengua y Literatura Hispánica. El acercamiento a la literatura española del siglo XVIII desde un enfoque de género motiva el interés del alumnado por un amplio número de obras de la época, no solo teatrales, a la vez que favorece el desarrollo del pensamiento crítico y la adquisición de competencias, así como el logro de los resultados de aprendizaje marcados.

Palabra clave: La familia a la moda; Ma Rosa de Gálvez; comedia neoclásica; Ilustración; enfoque de género; desarrollo didáctico.

\begin{abstract}
The article presents the study of the illustrated thematic motifs and the aesthetic characteristics of the neoclassical comedy of good customs applied to the work La familia a la moda, by $\mathrm{M}^{a}$ Rosa de Gálvez, as its analysis is carried out in the classroom within a subject of the Degree in Hispanic Language and Literature. The approach to Spanish Literature of the Eighteenth Century from a gender perspective motivates students' interest in a large number of works of the period, not only theatrical, while also promoting the development of critical thinking and the acquisition of skills, as well such as achieving marked learning outcomes.
\end{abstract}

Keywords: La familia a la moda; Ma Rosa de Gálvez; neoclassical comedy; Illustration; gender focus; didactic development.

\section{Introducción, objetivo y perspectiva teórica}

Las materias impartidas en las aulas universitarias quedan en ocasiones lejos de las circunstancias e intereses del alumnado, pese a los cambios en la estructura de los estudios universitarios, y a la introducción de la evaluación por competencias o de las tecnologías de la información y de nuevos sistemas de enseñanza-aprendizaje que se 
han producido en las últimas décadas. Esto ocurre de manera patente en la transmisión del saber sobre épocas concretas de la historia de la literatura, para las que un enfoque tradicional en la enseñanza de sus textos no siempre consigue que concienciemos al estudiantado de la importancia de los mismos.

Por ello se buscan y aplican nuevas metodologías didácticas y diferentes sistemas de evaluación, para lograr el objetivo final de que quienes se matriculan en carreras filológicas mantengan el interés por los estudios literarios y sigan leyendo, valorando, estudiando y concienciándose de la necesidad de mantener vigente las investigaciones y las ediciones de las obras todavía inéditas o carentes de buenas ediciones críticas. Con esa finalidad, resulta de utilidad el acercamiento al texto desde presupuestos de la teoría de la recepción, de los conceptos de horizonte de expectativas y horizonte de experiencias y desde el enfoque de género, apoyados en propuestas de actividades prácticas que favorezcan el estudio de las obras literarias como objetos estéticos y como productos históricos, a la vez que como discursos sociales que han ayudado a la construcción del sistema de pensamiento actual.

En este trabajo presento un planteamiento didáctico para la enseñanza de los modelos y el papel de las mujeres en la reforma ilustrada visto a través de los textos literarios españoles escritos en el siglo XVIII. Se trata de un tema desarrollado a partir de la lectura y análisis de la comedia de Ma Rosa Gálvez titulada La familia a la moda, dentro de una asignatura denominada "Literatura española de los siglos XVIII y XIX"

Antes de entrar en el tema del artículo, comenzaré presentando el esquema completo de la asignatura para completar el panorama y justificar un desarrollo transversal de algunos de los motivos ideológicos recogidos en la literatura de la época.

El temario está dividido en cuatro bloques, sobre los cuales se realizan las exposiciones de carácter más teórico e historicista con un planteamiento revisionista del canon establecido, y la realización de más de una decena de lecturas obligatorias de textos literarios, seis de los cuales son de lectura autónoma del estudiante fuera del aula, y sobre los cuales se realizan seis de las actividades prácticas de esta asignatura².

\footnotetext{
${ }^{1}$ De 6 créditos de carácter obligatorio dentro del plan de estudios del Grado en Lengua y Literatura Hispánica de la Universidad de La Rioja, se imparte durante el segundo semestre del $3^{\circ}$ curso. Está concebida con carácter de formación específica con el objeto de aportar a los estudiantes competencias en el conocimiento de la literatura española de esos dos siglos desde una visión historicista, a la vez que mediante el análisis de una selección de textos que ayudan a comprender las prácticas sociales, discursivas y culturales de su contexto de creación, así como todo lo relacionado con sus horizontes de recepción.

${ }^{2}$ Los otros textos literarios se leen y comentan durante las clases. El programa de la asignatura es público en la guía docente actualizada cada curso y disponible en https://www.unirioja.es/estudios/grados/lengua_hispanica/guias.shtml. Además de esa guía, existe una planificación temporal del programa también pública (documento llamado "cronograma"), pero en este caso sometida a consenso con los/las estudiantes al inicio del curso.
} 
A partir de las lecturas, la metodología 3 plantea un tratamiento transversal de los temas de la ideología ilustrada desde los cuales se revisa la literatura del siglo XVIII y parte de la producción literaria de la primera mitad del XIX, tratando de potenciar la motivación del alumnado, y que, además de estudiar, pueda reflexionar y debatir en clase sobre los temas explicados y su posible vigencia o repercusión en la sociedad de hoy.

Todo el temario se acompaña de un amplio listado de referencias bibliográficas que forman parte de la docencia de la asignatura, y que son comentadas con los y las estudiantes durante el desarrollo semestral del programa. Todos los materiales indicados para cada tema se encuentran a disposición del alumnado en un aula virtual4.

\section{Desarrollo de la propuesta práctica en el aula}

A partir de una reflexión sobre lo ya aprendido en temas previos (contexto histórico y sociocultural del siglo XVIII en España y Europa, temas y problemas de la literatura dieciochesca, el teatro posbarroco, la Poética de Ignacio de Luzán, la tragedia neoclásica5, y el punto 1 del esquema arriba recogido), explico la producción de $M^{a}$ Rosa Gálvez y, junto con el alumnado, que ha elaborado unas fichas de lectura, comentamos la obra La familia a la moda (argumento, personajes, temas de la obra y objetivo ilustrado, rasgos estéticos neoclásicos y otros aspectos estéticos, formales e ideológicos). Previamente, para preparar la lectura, les he recomendado que investiguen sobre la autora entrando en el portal que le dedica la Biblioteca Virtual Miguel de Cervantes ${ }^{6}$.

Introduzco en ese momento algunos contenidos que se irán desarrollando en sesiones posteriores 7 . Les proporciono además bibliografía y anexos, con resúmenes de obras que se comentarán a lo largo de las sesiones siguientes y con textos de otros

\footnotetext{
3 Respecto a la metodología del aprendizaje se articula en sesiones presenciales teóricas y prácticas, dentro de las cuales además de lecciones magistrales de la profesora y exposiciones de los estudiantes, realizamos tutorías en el aula, seminarios y visionamos documentales y representaciones teatrales de las obras estudiadas; y también están programadas actividades formativas no presenciales. En lo referido a la evaluación, siempre se lleva a cabo atendiendo a los objetivos generales de la asignatura y a las competencias específicas y destrezas señaladas, valorando la asistencia y participación activa en las actividades formativas presenciales y la realización de una prueba final (examen escrito o trabajo) en que el alumnado tiene que demostrar haber leído y comprendido los textos estudiados en clase, así como haber adquirido los conocimientos y alcanzado los objetivos previstos.
}

${ }^{4}$ El programa completo de la asignatura aborda la literatura española del siglo XVIII y de la primera mitad del siglo XIX. Este ejemplo docente se encuadra dentro del tema dedicado al teatro neoclásico, en un apartado sobre la comedia y dentro de un contexto de contenidos incluido en el Anexo I.

5 En sesiones previas al desarrollo de este tema, se ha leído y trabajado en clase La Raquel de Vicente García de la Huerta. Posteriormente a este tema los alumnos y las alumnas leerán y trabajaremos El delincuente honrado de Gaspar Melchor de Jovellanos.

6 Dirigido por Helena Establier Pérez se encuentra alojado en http://www.cervantesvirtual.com/obra/maria-rosa-de-galvez/ (Consulta: 15/04/2020).

7 Puntos 3, 4, 5 y 6 del esquema global de contenidos. Ver anexo I. 
autores/as neoclásicos/as y de otros pensadores/as ilustrados/as que debatieron sobre el papel social de la mujer en la familia y en la sociedad, así como temas anejos como la importancia de la educación o la defensa del trabajo.

El objetivo del tema programado es dar a conocer al alumnado la historia y los rasgos de la comedia neoclásica, su ideario ilustrado y su progresión hasta la comedia lacrimosa o drama sentimental en el último tercio del siglo XVIII y hacia la comedia burguesa en el siglo XIX. Pero, al partir de la lectura de esta comedia, de una autora, enfocamos el estudio haciendo hincapié en el interés que la literatura española del siglo XVIII mostró por el universo femenino, basado en el debate que los ilustrados europeos desarrollaron en torno al papel de la mujer en la sociedad. En la comedia neoclásica y con un objetivo reformista, se presentaron toda una serie de conflictos que afectaban a la construcción de los paradigmas de género masculino y femenino, mostrando el deseo ilustrado de educar a hombres y a mujeres para que cumplieran correctamente su función social y fueran ciudadanos útiles al Estado.

Para comprender la importancia que la cuestión de la educación y el papel de la mujer tiene en la literatura de ficción introduzco el debate social que promovieron los ilustrados acerca de su inserción en la esfera pública. La polémica tuvo especial interés dentro de la Sociedad Económica Matritense, en la que en octubre de 1775, don Manuel José Marín propuso el nombramiento de algunas damas como socias con el objeto de que sirvieran de modelo y estímulo para que otras muchas se implicasen en labores reformistas. Y un mes después esta propuesta sería apoyada por Pedro Rodríguez de Campomanes. Ellos abrieron el debate sobre la admisión de las mujeres en la Sociedad, que continuaría al año siguiente y que, tras varios años de silencio interno en la Sociedad, reabrirían don Francisco Cabarrús $^{8}$, en contra de su admisión, y Gaspar Melchor de Jovellanos9, a favor, en 1786. Y ese año ingresarían las dos primeras mujeres, María Isidra Quintana de Guzmán y de la Cerda, doctora el año anterior por la Universidad de Alcalá de Henares, y la Condesa-Duquesa de Benavente, María Josefa Alfonso Pimentel Téllez-Girón. Para una visión interna de ese universo femenino del Setecientos en España comento en clase y recomiendo a los/las estudiantes la lectura de dos textos de Josefa Amar y Borbón, el Discurso sobre la educación física y moral de las mujeres y el Discurso en defensa del talento de las mujeres, y de su actitud para el

\footnotetext{
${ }^{8}$ Cabarrús, Francisco, «Discurso sobre la admisión de señoras en la Sociedad Económica de Madrid»168 con un parecer negativo en extremo, publicado en el Memorial Literario en mayo de 1786 . En Memorial Literario, VIII, 29 (mayo de 1786), 74-85. (Se conserva el manuscrito en la Sociedad Económica de Madrid, leg. 73-44)

9 Jovellanos, «Discurso en que se prueba que las señoras deben ser admitidas por Socias, con las mismas formalidades y derechos que los demás individuos», publicado en el Memorial Literario en abril de 1786, en «Real Sociedad Económica Matritense de los Amigos del País», Memorial Literario, VII, 28 (abril 1786), 472-487.
} 
gobierno y otros cargos en que se emplean los hombres ${ }^{10}$. Y también proporciono bibliografía crítica actual que analiza esos discursos, como el artículo La mujer ilustrada en la España del siglo XVIII de Paloma Fernández Quintanilla o el libro de Emilio Palacios Fernández La mujer y las letras en la España del siglo XVIIIII.

Con el enfoque de género, al leer la comedia obligatoria y analizarla en el aula con el alumnado, e introducir yo numerosos ejemplos, con personajes y argumento de otras comedias y textos de la época, junto a cuestiones estructurales y estéticas, las y los estudiantes se interesan por la clara definición de roles pero también les sorprende que las obras muestren aspectos tales como el padecimiento de abusos de autoridad y de abusos físicos o la formación para la maternidad-embarazo, lactancia y crianza de los hijos-, además de otros como la capacidad intelectual de la mujer, su subordinación al hombre, su función social, su reclusión doméstica, o su responsabilidad en la educación moral de los hijos y las hijas. Motivos que aparecen recogidos en numerosos textos literarios de la época a los cuales voy haciendo referencia a lo largo del curso. Y, a la luz del tratamiento de todos esos temas en las comedias, y especialmente en la producción de $M^{a}$ Rosa Galvez, introduzco la figura de los personajes femeninos en sainetes y en algunas tragedias que ofrecen igualmente las distintas facetas que conforman el universo femenino.

En este último género, destaco el teatro heroico de protagonista femenina, muy bien recibido por las lectoras, que presenta a la mujer guerrera, determinada y equiparable al hombre en valor, en capacidad estratégica e incluso en fuerza física. Explico en clase que se trata de una idealización literaria que no se correspondía con la realidad, y que el género fue rechazado por los ilustrados ya que consideraban que atentaba contra la verosimilitud (especialmente por lo que se refería a los roles adoptados por las mujeres) y el decoro (por lo indecoroso de la vestimenta masculina por parte de las actrices). Para ejemplificar la teoría y los diferentes motivos arriba expuestos, refiero los argumentos y los roles de personajes masculinos y femeninos en las tragedias Blanca de Rossi o en Safo de Ma Rosa Gálvez, y La mujer de Padilla, doña María de Pacheco, de Ignacio García Malo; en El mayor rival de Roma: Viriato, de Luciano Francisco Comella (Dulcidia); y en la comedia Las esclavas amazonas y el drama El egoísta de Ma Rosa Gálvez, entre otros textos.

Con los objetivos de que el alumnado lea las obras y rastreen en ellas todas las características estéticas del teatro neoclásico, así como ideológicas del pensamiento ilustrado (respeto de las tres unidades, verosimilitud, decoro, justo medio, diálogos con gran carga ideológica, inicio de las obras ya en el desenlace de las acciones, pocos personajes en escena, valores socio-morales, finalidad didáctica, etc.), y que aprendan

\footnotetext{
${ }^{10}$ Amar y Borbón, Josefa, Discurso sobre la educación física y moral de las mujeres, Madrid, Cátedra, 1994. Y Discurso en defensa del talento de las mujeres, y de su actitud para el gobierno y otros cargos en que se emplean los hombres disponible en https://archive.org/details/discursosobrelaeooamaruoft/page/162.

${ }^{11}$ Ver las referencias bibliográficas en el listado final.
} 
a valorar la literatura del siglo XVIII y las razones para la inclusión o exclusión de textos y autores en la historia de la literatura, intento que el alumnado se interese por cómo el tratamiento literario de esos temas en la España de aquel momento ha repercutido en la configuración de la sociedad actual. Para ello propicio un debate sobre el trato que Madama Pimpleas da a su hija en La familia a la moda, y lo comparamos con la relación entre Paquita y doña Irene en El sí de las niñas de Leandro Fernández de Moratín. Lo enlazamos con el motivo de los conciertos matrimoniales y, este a su vez, con el tema del cortejo y la fidelidad conyugal, para llegar a reflexionar sobre otros como las razones de los bajos índices de natalidad, y, en especial, de qué manera un motivo como el maltrato machista estuvo también presente en la literatura dieciochesca española. Leemos en clase el sainete Las mujeres solas de María de Cabañas, y explico los argumentos de $E$ l egoísta, de $\mathrm{M}^{a}$ Rosa Gálvez (Milord Sidney, maltrata y trata de envenenar a su esposa Nancy, mujer que padece además por cómo repercute ese mal padre en su hijo); de El celoso don Lesmes, de Vicente Rodríguez Arellano (comedia de estética posbarroca en la que Marcela se ve sometida desde el mismo día de su boda con don Lesmes a una injusta reclusión a la que); de Blanca de Rossi, tragedia de $\mathrm{M}^{\mathrm{a}}$ Rosa Gálvez (Acciolino intenta poseer a la fuerza a Blanca); y de las novelas sentimentales Lisandro y Rosaura, de García Malo, o Sabina o los grandes sin disfraz, de Pablo Olavide (con casos extremos de maltrato físico) ${ }^{12}$.

También leemos en clase algún fragmento del discurso "Defensa de las mujeres" que publicó Feijoo dentro de su Teatro crítico universal, que inició en España, la polémica sobre el valor y el papel social de la mujer (y recomiendo la lectura autónoma de otros, como los antes citados de Amar y Borbón, Martí, Campomanes, Cabarrús, Jovellanos o Clavijo y Fajardo) preparando una actividad de debate real en el aula, en el que las y los alumnos adopten el rol de estos pensadores y puedan exponer su opinión de manera fundamentada con argumentos a favor y en contra de la promoción social de la mujer. La actividad, unida a la lectura de La familia a la moda y a todas las obras comentadas en clase hasta el momento, permite que conozcan bien cómo era el universo femenino de la época, y, en general la mentalidad y los usos y costumbres de la sociedad, que se trasladan a escena en la comedia neoclásica.

En esta actividad de debate se argumenta también sobre las propuestas de reforma de los ilustrados y su búsqueda de ciudadanos y ciudadanas útiles al Estado, llegando el alumnado por sí mismo a la conclusión de que el resultado que nos ofrece la literatura ilustrada y más en concreto la comedia neoclásica ensalzará a la esposa perfecta, diestra en el gobierno de la casa y buena madre de familia, del que resulta el conocido

\footnotetext{
${ }^{12}$ Estos últimos son analizados Pilar Pérez Pacheco en "La mujer del setecientos: entre la educación y la costumbre. Hacia una nueva lectura de Amar y Borbón, Cadalso, Moratín y Jovellanos", en Campus Stellae. Haciendo camino en la investigación literaria, en Dolores Fernández López y Fernando RodríguezGallego (coords.), Universidad de Santiago de Compostela, Vol. I., 2006, 487-495.
} 
modelo de "ángel del hogar", mujer doméstica que protagonizará la posterior novela de la Restauración y que fue ya dibujado en La perfecta casada por Fray Luis de León. Y al lado de esta mujer, de la misma forma se comprenderá cómo es el modelo masculino: un hombre de bien se caracteriza por ser buen hijo y/o buen padre dentro del ámbito familiar, $y$, en el espacio social, se considera buen ciudadano a aquel hombre trabajador, responsable y disciplinado, prudente y comprensivo e indulgente con los errores de los demás, a la vez que moderado en sus costumbres y exigente consigo mismo. Porque si bien enfocamos el estudio del tema en la mujer, necesariamente se define a su vez la identidad masculina y se puede comprobar que el teatro pone en escena a hombres y mujeres cuyas conductas se convierten en ejemplos que seguir, así como otros modelos detestables, ajustándose los autores y las autoras al objetivo didáctico moral y de instrucción pública que se espera de la literatura en esa etapa.

En general, el acercamiento a los textos desde esta óptica ideológica a través de cuestiones cercanas a los intereses de la sociedad actual, suele captar la atención de los/las estudiantes, que realizan con gusto las lecturas obligatorias y algunas de las recomendadas. Sobra decir que este enfoque se apoya en las raíces estéticas e histórico-literarias de cada uno de los textos analizados, aspecto que sigue siendo objetivo prioritario en su estudio.

Para profundizar en los roles femenino y masculino de la época, así como en las costumbres sociales que la comedia neoclásica muestra y que son objeto de denuncia por ilustrados y moralistas, contrastamos los antimodelos de Faustino y su padre don Canuto con los modelos del joven Carlos y su padre don Facundo, personajes de La familia a la moda, y relaciono ambos con los dibujados por Iriarte en El señorito mimado. Los vicios de los hijos se deben en ambas obras a su falta de formación, de la que no se ha preocupado correctamente su madre, responsables de la misma. Pero no quedan siempre libres de culpa los hombres de la casa: Don Canuto, ocupado en su propia diversión no ha vigilado cómo su esposa gobernada y educaba a los hijos. En el caso de doña Dominga, madre de don Mariano, se trata de una mujer viuda (El señorito mimado). Al analizar a los jóvenes protagonistas de esas obras, y al igual que con don Canuto y con don Gonzalo (el padre en La señorita malcriada, también de Iriarte), explico el tema de la ociosidad de las clases acomodadas con las consiguientes consecuencias nefastas tanto para la economía doméstica como para el Estado, ejemplificadas en la desestructuración del núcleo familiar. Tanto don Canuto, como Faustino y madama Pimpleas son causantes en la misma medida de la ruina familiar; mientras ellos derrochan la fortuna en el juego y la asistencia a fiestas, la madre gasta desaforadamente en estar a la moda. Esa crítica a la ociosidad, así como los excesos frívolos en el cuidado de la apariencia física se ridiculiza al extremo en La familia a la moda, atacando tanto un gasto tan excesivo y pernicioso para la economía del hogar como la indecencia moral de la moda afrancesada en el vestir: el criado Pablo critica el 
escote de la criada Teresa, que dice haberse resfriado por tener que madrugar cuando, en opinión de Pablo, ha sido por el desaforado escote que luce.

El primer ejemplo de esta moda frívola lo comentamos en La petimetra de Nicolás Fernández de Moratín, al igual que vemos en esa comedia una crítica paralela a los petimetres. Los hombres eran esclavos de las modas, como también refleja el sainete Las mujeres solas, pero se culpabiliza a la mujer de la ruina familiar. Así, en el sainete $L a$ petimetra burlada se presenta la figura del marido agobiado por el desenfrenado deseo de lujos de la esposa. En otro sainete, La bella madre, esa frivolidad se parodia en el caso de una madre que trata de forma muy desigual a sus cuatro hijas, mimando a los dos que, como ella, son petimetras, y despreciando a las otras dos que prefieren ser mujeres de su casa y destinar su tiempo a leer y a realizar tareas domésticas. Su pésima actitud se manifiesta en preferir a la criada antes que a estas dos hijas y en procurar ocultarlas de las visitas. Estas dos últimas obras, al ser sainetes, las leemos en el aula.

Paralelo a la preocupación frívola por el aspecto, suele mostrarse en esta literatura el desinterés de las jóvenes en adquirir una educación seria, como ejemplifica un parlamento de Pepita en La señorita malcriada que proporciono al alumnado ${ }^{13}$. Puesto que ello sirve para tratar esa preocupación de los intelectuales ilustrados, comentamos el mismo desinterés en los jóvenes y remito a la carta VII de las Cartas marruecas de Cadalso, y a la Satira II A Arnesto de Jovellanos, que se leen en clase en otro momento del curso.

Pero estrictamente respecto a las mujeres, relaciono el destino de todas las protagonistas modélicas de las comedias con ejemplos de la literatura europea y aludo al dibujado por Rousseau en 1762 en Emilio o la educación: deben ser criadas para agradar y ser útiles al hombre, ser dignas de su amor y protección, educarlos en su niñez, y saber acompañarlos en su vida adulta, cuidándolos, aconsejándolos, consolándolos, $y$, en definitiva, haciendo que sus vidas sean más gratas. Es el destino de Paquita en El sí de las niñas; o el de Isabel, en Los figurones literarios, de Ma Rosa Gálvez. Y pese a ese papel de educadoras de los hijos e hijas, esencialmente en cuestiones morales, sin embargo, la despreocupación de los jóvenes por su formación y el alto índice de analfabetismo, especialmente entre las mujeres, aunque no sólo entre el género femenino se destaca en muchas de las comedias de la época. En Donde menos se piensa salta la liebre, zarzuela en un acto de Tomás de Iriarte, Pascuala y Gregoria, payas hijas del boticario señor Onofre, no saben leer ni escribir, y aprenden por voluntad propia pero solamente para poder cartearse con sus galanes. Pepita (La señorita

\footnotetext{
13 "Da PEPITA: Oye, otra cosa me ocurre. / por si acaso hay hombres raros, / como ese buen don Eugenio, / que se quejen de que estamos / por conquistar, y pretendan / que debemos saber algo, / ya procuraré tener / algunos libros sembrados / o cerca del tocador / o en las mesas. Ostentando / que leemos, basta; y luego / que vengan a averiguarlo. / En nuestras conversaciones / ya ves que no fatigamos / el discurso. Cuando alguna / se vaya formalizando, / con un ya, bien, ¿pues no digo?, / estamos fuera del paso. / Lo mismo hacen muchos hombres, / y los llaman ilustrados." La señorita malcriada, acto III, escena VII.
} 
malcriada), Mariquilla y Rita (las dos hijas petimetras de La bella madre) son ejemplos de la falta de interés por cultivar su mente de algunas mujeres de la época. Pero frente a esos antimodelos, la comedia neoclásica ofrecía también otros ejemplos de mujeres que sí estaban interesadas en los libros, como Luisa (otra de las hijas de La bella madre) o, más que ello, en adquirir una buena base de cultura, como doña Laura, (La sabia indiscreta, de María Lorenza de los Ríos). Y la preocupación de los ilustrados por la educación de la mujer la desarrolla de forma muy amena Pedro de Montengón en su novela Eudoxia, hija de Belisario, a través del contraste entre tres personajes femeninos: la maestra Domitila, la joven Eudoxia, su pupila, y la madre de esta, Antonina.

A pesar de la importancia concedida al papel desempeñado por la madre en la educación sociomoral de sus hijos y en el buen gobierno de una casa, tanto La familia a la moda, que es el objeto primero de lectura y análisis, como todas las otras obras que voy citando y a las que nos acercamos a través de sus argumentos y de la lectura y comentario de fragmentos, ponen de manifiesto que se la preparaba para cumplir adecuadamente con el objetivo que se les marcaba, pese a lo cual el fracaso era suyo, si bien, coherentemente se responsabilizaba en primer término al esposo que, entregado al trabajo o al ocio, no vigilaba el buen o mal hacer de su esposa y el gobierno o desgobierno de su casa. Así se ve en el trío de don Canuto, Madama Pimpleas y Faustino en La familia a la moda, en la comedia La madre hipócrita de Juan Ignacio González del Castillo y en el sainete La falsa devota de Ramón de la Cruz. Caso algo diferente es doña Dominga de El señorito mimado porque, como he mencionado, es viuda; sin embargo, la suya es una muestra más de la necesidad de que el hombre supervise, vigile y encamina los pasos de la mujer, incapaz de llegar a ser el deseado modelo de buena ciudadana por sí sola, sin la compañía de un hombre a su lado.

La familia a la moda permite trabajar con el alumnado los temas hasta el momento mencionados, así como otros de interés en la época cuyo debate interesa especialmente al actual estudiantado: la posibilidad de que la mujer adopte un nuevo rol social que conlleva la alteración de ciertos valores morales de larga tradición, como el que los matrimonios a la moda llevasen sus vidas por separado (La familia a la moda); el fenómeno de los cortejos/amistades masculinas, que podía derivar en adulterios encubiertos (insinuado en La familia a la moda y en La señorita malcriada); el descenso de la tasa de natalidad (la mayoría de las comedias presentan familias con uno o dos hijos, máximo cuatro en alguna). Es excepcional en este aspecto el caso de doña Irene, la madre en El sí de las niñas, que dio a luz veintidós hijos, de los cuales solo Paquita ha sobrevivido. Y su ejemplo nos sirve para analizar en clase otra cuestión social que preocupaba en la España del setecientos: la falta de formación en cuestiones de salud y el inicio de un acertado interés por el bienestar físico, de gran relevancia en lo referido a los cuidados del embarazo y del recién nacido. Para comentar este motivo leemos en el aula el sainete cómico La embarazada ridícula, de Ramón de la Cruz. Y ponemos todos los temas mencionados en relación con los discursos de Amar y Borbón y con la crítica 
que Tediato hace de varios de ellos en las Noches lúgubres ${ }^{14}$. Contrastamos los modelos y los antimodelos de mujer a partir de las lecturas obligatorias, de los argumentos que explico en el aula sobre las demás referencias literarias que doy, y de fragmentos que proporciono con orientaciones formales y de contenido para leer y analizar en clase.

Así, el alumnado conoce a las prudentes doña Guiomar de La familia a la moda, y doña Clara de La señorita malcriada; a las hacendosas Alfonsa y Luisa, de La bella madre, donde la primera encarna a la mujer doméstica y la segunda a la mujer que aspira a una vida contemplativa, y a Laura de La sabia indiscreta, que desprecia el amor y se interesa por los libros. Se comparan estos personajes con sus antimodelos en las mismas obras, como sucede por ejemplo con doña Clara y doña Inés, las primas que protagonizan La mojigata.

Unas y otras tienen en la literatura de la época un objetivo común: el matrimonio. Se muestra como el estado más conveniente para cualquier mujer, además de ser considerado institución necesaria para la buena organización del Estado, pues es dentro de él desde donde se favorece el aumento de la población del país. El matrimonio no solo es conveniente para la mujer, sino que se presenta como el mejor premio a su virtud en la mayoría de los textos teatrales. Un claro ejemplo es el citado sainete La bella madre, en el que las dos petimetras son despreciadas por sus acompañantes, en los cuales creían tener a sus futuros esposos, mientras que las dos hijas despreciadas por su recato y domesticidad son bendecidas inesperadamente con dos matrimonios ventajosos y honorables.

En la época, como muestran las comedias referidas, se practicaba habitualmente el matrimonio concertado. $Y$ ese motivo nos permite no solo analizar a los personajes implicados en esas tramas (padre o madres que eligen la pareja e hijos e hijas que deben contraer ese matrimonio), sino la problemática del correcto entendimiento del tema del respeto a la autoridad, el alcance del concepto de despotismo ilustrado, la cuestión de si los/as hijos/as deben acatar el dictado de sus progenitores o si tienen libertad de elección. Como muestra de que el tema sigue presente en la sociedad del siglo XXI, y para implicar más al alumnado en esta reflexión, les muestro noticias recientes o algún video de pocos minutos sobre la vigencia de los matrimonios concertados en culturas que no son la española, como la hindú15. Respecto a las comedias neoclásicas españolas, tenemos los ejemplos de madama Pimpleas que quiere deshacer el matrimonio ya concertado entre su hija Inés y don Carlos, e intenta imponer la boda

\footnotetext{
${ }^{14}$ En este punto, dado que la asignatura parte de una visión historicista del estudio de la literatura del setecientos y del ochocientos, remito a esa otra lectura obligatoria del curso, a la que se dedican también algunas sesiones prácticas, y se comentan las críticas de Tediato hacia madres y padres.

15 "India celebra diez millones de bodas al año sin amor (y nadie se divorcia). Tres de cada cuatro jóvenes declaran preferir un casamiento acordado por las familias en vez de un romance 'a la occidental'." En https://www.elespanol.com/mundo/asia/20181013/india-celebra-millones-bodas-sin-nadiedivorcia/344966323_o.html (Consulta: 28/01/2020)
} 
entre Inés y el marqués, que le conviene más socialmente. Un caso similar sucede en la novela Eudoxia de Montengón. En El señorito mimado, en El sí de las niñas, en La mojigata, en el sainete La oposición a cortejo, entre otras obras, aparecerá el mismo motivo.

Parejo al estudio de este motivo de los matrimonios concertados en algunas comedias y sainetes aparecerá también el tradicional conflicto de los celos. Así se ve, por ejemplo, en las ya mencionadas obras de La sabia indiscreta o de El celoso don Lesmes, como en También lidia una mujer con otra mujer por celos, de Bernardo Vicente Lobón y Carrillo.

Y de forma innovadora y subversiva, leemos en el aula, para contrastar, el curioso sainete de María de Cabañas, Las mujeres solas, que muestra de manera humorística que, al igual que las mujeres solteras desean encontrar marido, las casadas, a menudo, querrían perderlos de vista. En ese breve texto de autoría femenina, como indiqué arriba, se presenta además una denuncia a los malos tratos dentro del matrimonio que sufrían a menudo las esposas.

Es frecuente encontrar ejemplos en la literatura del setecientos que tratan el motivo de los abusos de autoridad por parte de los padres hacia sus hijas, y en ellos se muestra que estos pueden llegar a graves extremos, encontrando en todos los géneros (comedias, sainetes, tragedias, novelas sentimentales...) muestras no ya solo de matrimonios impuestos a cualquier coste, sino también de violencia hacia las hijas y hacia las esposas, que llegan incluso a testimoniar violaciones. Un testimonio no trágico se puede leer en el aula el sainete La elección de novios, de Antonio Rezano Imperial, que manifiesta en tono cómico la consideración de la mujer como un objeto al presentar a un tutor que para casar a su pupila anuncia públicamente que quienes estén interesados en el negocio se presenten ante él.

Aunque es menos habitual, estos abusos de autoridad pueden afectar también a los hijos varones, como trata el drama trágico en un acto de Ma Rosa Gálvez titulado Safo.

\section{Conclusiones}

En todas las obras que presento a los estudiantes, encontramos no solo la defensa de preocupaciones ilustradas, sino el paradigma de comedia de buenas costumbres: la defensa del núcleo familiar, del respeto a normas morales tradicionales frente a las costumbres modernas más públicas y frivolas, de la necesidad de que los cabezas de familia dirijan prudentemente sus hogares y de que las madres se encarguen convenientemente de sus casas y de sus hijos; la importancia y relación de la formación de la mujer con la preparación para la maternidad y sus responsabilidades; la contraposición entre el modelo de hombre ciudadano de bien y el tarambana, así como la confrontación entre la mujer prudente, responsable y hogareña frente a la moderna petimetra. En todas se destaca que la responsabilidad de la mujer para con el Estado era desempeñada en la célula familiar y que su aportación más valiosa son los hijos 
sanos en cuerpo y espíritu. $Y$ en todas se estructuran los argumentos respetando las normas neoclásicas ya recogidas en la Poética de Luzán: unidades de acción, tiempo y espacio; triunfo de la razón, del buen gusto, del decoro, de la verosimilitud entendidos estos conceptos bajo la óptica reformista ilustrada; premio de la virtud y castigo de los modelos que contravienen la moral y que perjudican al bien social; así como decorado y puesta en escena sencillos, aspectos que son contrastados con comedias de magia, como El anillo de Giges, y con los dramas románticos posteriores, como La conjuración de Venecia.

En todos los textos se refleja cómo afectan los motivos literaturizados a la construcción de unos paradigmas de identidad masculina y femenina. En los últimos años, para motivar a los y las alumnas, nos acercamos en varios de los aspectos tratados al debate de género e incluso, en sesiones posteriores dedicadas a la literatura romántica decimonónica, volvemos sobre este tema para debatir sobre el mito del amor romántico. La polémica que en la España del Setecientos abrió Feijoo, con su posterior desarrollo en la prensa, cartas, memorias, ensayos y literatura de ficción, y que rastreamos perfectamente en los ejemplos de comedias y sainetes neoclásicos que trato en el aula, me permite darles a conocer un amplio número de obras y analizar en ellas cuestiones puramente literarias, además de esas otras sociales que, por otro lado, interesaban a los autores ilustrados del momento. Queda claro en lo expuesto, que el corpus de obras que presento es reducido, respecto al que se podría trabajar. Esto se debe, como se puede suponer, a la limitación temporal, que obliga a centrar el tema de la comedia en una única lectura obligatoria para su lectura y análisis y a la lectura de fragmentos de las otras dentro del aula.

Para completar el enfoque de género en este punto del programa, como muestra el índice del tema que arriba presenté, además de hacer partir el estudio del tema de la lectura de una comedia escrita por una mujer, y de leer en el aula otros dos sainetes de otras dos autoras, dedico una sesión a explicar la producción de otras escritoras de la literatura española del siglo XVIII, aunque, por cuestiones de tiempo y programa, tras una somera introducción panorámica, proporciono a los y las estudiantes un anexo con un listado de autoras catalogado por géneros, y referencias bibliográficas en las que pueden ampliar información si lo desean. Este enfoque, de evidente vigencia en la actual sociedad acerca al alumnado a unos textos literarios de fuerte carga ideológica que reciben inicialmente con prejuicios y desinterés, pero su visión cambia al invitarles a un debate que en cierta medida los propios ilustrados promovieron. La propuesta es que los/las estudiantes lean las obras desde una doble perspectiva: como miembros ilustrados de la sociedad que los genera y como lectores del siglo XXI que encuentran en esos textos conexiones con la concepción vigente de roles de género y de otros familiares, sociales y culturales. Concluyo con algo que repito habitualmente a mis alumnos/as: el lema clásico "sapere aude". Sin perder de vista el rigor académico necesario para el estudio dogmático de la obra, les invito a que entre todos si bien no 
establezcamos un nuevo canon en la historia de la literatura española, al menos, añadamos anexos al ya existente y a su interpretación.

Como cierre de la lección y conclusión de este artículo, todo su desarrollo se apoya en la bibliografía recomendada que proporciono a las/los estudiantes.

\section{Bibliografía}

Acereda, A. (1997). Una comedia inédita de la Ilustración española: La sabia indiscreta de la marquesa de Fuerte Híjar. Dieciocho, 20.2, 231-262.

Albiac Blanco, M. D. (2007). Viejos, niñas y cánones en el teatro de Moratín (El viejo y la niña en "El sí de las niñas"). Cuadernos de Historia Moderna. Anejos, VI, 37-58.

Amar y Borbón, J. (1994). Discurso sobre la educación física y moral de las mujeres. Madrid,España: Cátedra.

Amar y Borbón, J. (1790). Discurso en defensa del talento de las mujeres, y de su actitud para el gobierno y otros cargos en que se emplean los hombres, Madrid, Benito Cano; XL+349 ; 80.Madrid, Biblioteca Nacional de España, 2-269745. Recuperado de: http://www.bieses.net/wpcontent/uploads/2016/03/amaryborbon_discurso_1790.pdf

Ángula Egea, M. (2006). Virtuosa, casta y heroica. La mujer española en el melólogo del siglo XVIII". Revista de Literatura, LXVIII (136), 471-488.

Cabañas, María (1997). Las mujeres solas, ed. de Fernando Doménech Rico. Madrid, España: Biblioteca Nueva.

Cadalso, J. (2015): Cartas marruecas, ed. de Ignacio Arellano Torres. Nueva York: Instituto de Estudios Auriseculares (IDEA).

Cañas Murillo, J. (2000). Tipología de los personajes en la comedia española de buenas costumbres. Cáceres, España: Universidad de Extremadura.

Cañizares, J. (1983). El anillo de Giges, ed. de Joaquín Álvarez Barrientos. Madrid, España: Consejo Superior de Investigaciones Científicas.

Comella, L.F. (17-?). El mayor rival de Roma: Viriato, edición digital basada en la edición de Cádiz, en la Imprenta de Marina, [17-?]. Recuperado de: http://www.cervantesvirtual.com/obra-visor/el-mayor-rival-de-roma-viriatodrama-tragico-en-un-acto--o/html/ff11gba2-82b1-11df-acc7002185ce6064_1.htm\#1.

De Iriarte, T. (1978). El señorito mimado, ed. de Russell P. Sebold. Madrid, España: Castalia.

De Iriarte, T. (1978). La señorita malcriada, ed. de Russell P. Sebold. Madrid, España: Castalia.

De La Cruz, R. (1915). La bella madre, en Sainetes de Don Ramón de la Cruz en su mayoría inéditos, colección ordenada por D. Emilio Cotarelo y Mori, Tomo I. Madrid, 
España: Bailly-Bailliere, 139-143, (Nueva Biblioteca de Autores Españoles; 23). Recuperado de:

http://www.cervantesvirtual.com/portales/ramon_de_la_cruz/obra-visor/labella-madre-sainete-nuevo--o/html/9c32953c-6ao2-4aco-838b6co45c6846b3_2.html\#I_o_(Consulta: 26/01/2020)

De La Cruz, R. (1811). La embarazada ridícula, edición digital basada en la edición de Valencia, José Ferrer de Orga y Compañía. Recuperado de: http://www.cervantesvirtual.com/obra-visor/la-embarazada-ridicula-sainetenuevo-para-doce-personas--o/html/ff1azafo-82b1-11df-acc7002185ce6064_2.html\#I_o_

De La Cruz, R. (1813). La falsa devota, edición digital basada en la edición de Valencia, José Ferrer de Orga. Recuperado de: http://www.cervantesvirtual.com/obravisor/la-falsa-devota-sainete-nuevo-para-once-personas--o/html/ff142bo682b1-11df-acc7-002185ce6064_2.html\#I_o_

De La Cruz, R. (1915). La oposición a cortejo, en Sainetes de Don Ramón de la Cruz en su mayoría inéditos. Madrid, Bailly-Bailliere, 1915-1928 (Nueva Biblioteca de Autores Españoles; 23 y 26). Edición digital a partir de la de Emilio Cotarelo y Mori. Recuperado de: http://www.cervantesvirtual.com/obra/la-oposicion-acortejo--o/_(Consulta: 28/01/2020)

De León, F.L. (1980). La perfecta casada. Madrid, España: Espasa Calpe.

De Los Ríos y Loyo Fuerte-Híjar, M.L. (2000). La Marquesa de Fuerte Hijar, una dramaturga de la llustración: (estudio y edición de La sabia indiscreta), edición de Alberto Acereda. Cádiz, España: Servicio de Publicaciones de la Universidad de Cádiz.

Deacon, P. (2007). Arte y realidad en El sí de las niñas de Leandro Fernández de Moratín. Cuadernos de Historia Moderna, VI, 87-97.

Díaz Marcos, A.M.(2009). Viejas ladinas, petimetras finas: (des)obediencia y transgresión en "La familia a la moda" de María Rosa Gálvez. Dieciocho: Hispanic enlightenment, 32.2, 333-350.

Doménech, F. (1997). Antología del teatro breve español del siglo XVIII. Madrid, España: Biblioteca Nueva.

Establier Pérez, H. (2006). Una dramaturga feminista para el siglo XVIII: las obras de Ma Rosa Gálvez de Cabrera en la comedia de costumbres ilustrada. Dieciocho, 29.2, 179-203.

Feijoo, B.J. (1986). "Defensa de las mujeres" en Teatro crítico universal o discursos varios en todo género de materias, para desengaño de errores comunes, Edición, introducción y notas de Giovanni Stiffoni. Madrid, España: Castalia. 
Fernández Cabezón, R. (2003). La mujer guerrera en el teatro español de fines del siglo XVIII. Anuario de Estudios Filológicos, vol. XXVI, 117-136.

Fernández de Moratín, L. (2010). El sí de las niñas, ed. de Emilio Martínez Mata. Madrid, España: Cátedra.

Fernández de Moratín, N. (1989). La petimetra, edición, introducción y notas de Jesús Cañas Murillo. Badajoz, Universidad de Extremadura.

Fernández Quintanilla, P. (1981). La mujer ilustrada en la España del siglo XVIII. Madrid, España: Ministerio de Cultura.

Franco Rubio, G. A. (2001). "Nicolás Fernández de Moratín y El arte de las putas". Feminismo y misoginia en la literatura española: fuentes literarias para la historia de las mujeres, Cristina Segura Graíño (aut.), Árbol académico, 97-122.

Franco Rubio, G. A. (2007). La contribución literaria de Moratín y otros hombres de letras al modelo de mujer doméstica. Cuadernos de Historia Moderna, Anejos, VI, 221-254.

Franco Rubio, G.A. (2010). Tomás de Iriarte y La señorita malcriada: Retóricas e imágenes literarias sobre la mujer doméstica a finales del siglo XVIII. En Cristina Segura Graíño (coord. ). La Querella de las mujeres: Análisis de textos, Árbol académico, 149-179.

Franco Rubio, G.A. (2015). Las mujeres en el debate social sobre los matrimonios en la España del siglo XVIII". La Aljaba, segunda época, vol. XIX, 37-54.

García Malo, I. (1997). La mujer de Padilla, doña María de Pacheco, ed. de Guillermo Carnero, Madrid, España: Cátedra.

Gálvez, M.R. (2001). La familia a la moda, ed. de René Andioc. Cádiz, España: Plaza Universitaria Ediciones y Servicio de Publicaciones Universidad de Cádiz.

Gálvez, M.R. (1804). Los figurones literarios, edición digital a partir de Obras poéticas. Tomo I, Madrid, Imprenta Real, 237-366. Recuperado de: http://www.cervantesvirtual.com/portales/maria_rosa_de_galvez/obravisor/los-figurones-literarios-comedia-original-en-tres-actos/html/dcd22a622dc6-11e2-b417-000475f5bda5_2.html\#I_o_(Consulta: 15/04/2020).

Gálvez, M.R. (1804). El egoísta, edición digital a partir de Obras poéticas. Tomo I, Madrid, Imprenta Real, 111-236. Recuperado de: http://www.cervantesvirtual.com/portales/maria_rosa_de_galvez/obravisor/el-egoista-comedia-original-en-tres-actos/html/dcd22724-2dc6-11e2b417-000475f5bda5_2.html\#I_o_(Consulta: 15/04/2020).

Gálvez, M.R. (1995). Safo, ed. de Fernando Doménech. Madrid, España: Asociación de Directores de Escena.

Gálvez, M.R. (1804). Blanca de Rosi, edición digital a partir de Obras poéticas. Tomo II, Madrid, Imprenta Real, 132-234. Recuperado de: http://www.cervantesvirtual.com/portales/maria_rosa_de_galvez/obra- 
visor/blanca-de-rossi-tragedia-en-cinco-actos/html/5fcfae8a-obdo-11e2-b1fboo163ebf5e63_2.html\#I_o_(Consulta: 15/04/2020).

Gálvez, M.R. (-). Las esclavas amazonas, reproducción digital del manuscrito original. Localización: Biblioteca Nacional de España. Sig.: Ms. 16507. Recuperado de: http://www.cervantesvirtual.com/portales/maria_rosa_de_galvez/obra/lasesclavas-amazonas/ (Consulta: 15/04/2020).

Gomis Coloma, J. (2009). Romances conyugales: buenas y malas esposas en la literatura popular del siglo XVIII. Tiempos Modernos 18 (1), Monográfico El matrimonio en el corazón de la sociedad.

González del Castillo, J.I. (1914). La madre hipócrita, edición digital a partir de Obras Completas. Tomo III. Madrid, Librería de los Sucesores de Hernando, 69-152. Recuperado de: http://www.cervantesvirtual.com/obra-visor/la-madrehipocrita-comedia-en-tres-actos--o/html/ff1810oe-82b1-11df-acc7002185ce6064_1.htm\#1 (Consulta: 15/04/2020).

Huguet Santos, M. (1989). La mujer española del siglo XVIII en la obra de Josefa Amar. Boletín de la Institución Libre de Enseñanza, nº 7, 43-57.

Jovellanos, G.M. (1784). Dictamen de Don Gaspar Melchor de Jovellanos en la leal Junta de Comercio en el expediente seguido a instancia fiscal, sobre renovar o revocar la prohibición de la introducción y uso de las muselinas, Obras completas, I, Barcelona, España: Librería La Anticuaria, X, 267-304. (La mujer en relación al lujo, la moda y las costumbres...).

Jovellanos, G.M. (1785). Informe a la Junta General de Comercio y Moneda sobre la libertad de las artes, Obras completas, I, Barcelona, España: Librería La Anticuaria, $X, 509-539$ ). Sobre todo: $5^{\circ} \mathrm{p}^{\circ}$ y siguientes, $X, 510$ (liberalización de su trabajo).

Jovellanos, G.M. (1986). Memoria leída en la Sociedad Económica de Madrid sobre si debían o no admitir en ella a las señoras. $B A E, I I, 54-56$.

Jovellanos, G.M. (1865). "Contra la tiranía de los maridos" (Sátira quinta. Obras completas, I, Barcelona, España: Librería La Anticuaria, 293-297).

Lobón y Carrillo, B.V. (1799). También lidia una mujer con otra mujer por celos, edición digital basada en la edición de [Madrid], Librería de Don Isidro López. Recuperado de: http://www.cervantesvirtual.com/obra-visor/tambien-lidiauna-mujer-con-otra-mujer-por-celos-funcion-casera-o-comica-diversion-parasolas-cuatro-mujeres/html/ff15a5b2-82b1-11df-acc7-002185ce6064_1.html\#1.

López-Cordón C. (2005). Condición femenina y razón ilustrada. Josefa Amar y Borbón. Zaragoza, España: Prensas Universitarias de Zaragoza.

Luzán, I. (2008). La Poética, ed. de Russell P. Sebold. Madrid, España: Cátedra. 
Martín Gaite, C. (1991). Usos amorosos del dieciocho en España. Barcelona, España: Anagrama.

Martínez López, M. (2010). La imagen de la mujer en la literatura española del siglo XVIII: Paradigmas de género en la comedia neoclásica. Anagnórisis: Revista de investigación teatral, №. 1 (Ejemplar dedicado a: Las mujeres en el teatro), 5986.

Montengón, P., Eudoxia, hija de Belisario (1793), edición digital basada en la de Madrid, Antonio Sancha. Recuperado de: http://www.cervantesvirtual.com/obravisor/eudoxia-hija-de-belisario--o/html/ffo7bb3c-82b1-11df-acc7002185ce6064_1.htm\#I_1_(Consulta: 15/04/2020).

Morant Deusa, I. y Bolufer Peruga, M. (1996). Sobre la razón, la educación y el amor de las mujeres: mujeres y hombres en la España y en la Francia de las Luces. Studia Historica, Historia Moderna, 15, 179-208.

Narciso García-Plata, R. (2002). Nueva aproximación al estudio del recurso del contraste en la tragedia neoclásica: los personajes". Anuario de Estudios Filológicos, XXV, 327-343.

Nieman De Giraud, R. y Figueroa, M. (2001-2002). Leandro Fernández de Moratín y Pedro Motengón y Paret: un discurso sobre la mujer a fines del siglo XVIII. Fundación, 5, 317-328.

Palacios Fernández, E. (2002). La mujer y las letras en la España del siglo XVIII. Madrid, España: Ediciones del Laberinto.

Palacios Fernández, E. (2000). Noticia sobre el parnaso dramático femenino en el siglo XVIII. En Luciano García Lorenzo (ed.), Autoras y actrices en la historia del teatro español. Murcia, España: Universidad de Murcia, Servicio de Publicaciones, 81132.

Pérez Pacheco, P. (2006). La mujer del setecientos: entre la educación y la costumbre. Hacia una nueva lectura de Amar y Borbón, Cadalso, Moratín y Jovellanos. En Dolores Fernández López y Fernando Rodríguez-Gallego (coords.), Campus Stellae. Haciendo camino en la investigación literaria. Santiago de Compostela, España: Universidad de Santiago de Compostela, I, 487-495.

Puleo, A. H. (1993). La ilustración olvidada. La polémica de los sexos en el siglo XVIII. Madrid, España: Anthropos.

Rodríguez Arellano, V. (1790). El celoso don Lesmes, edición digital basada en la edición de [Madrid], se hallará en la Librería de Castillo. Localización: Biblioteca de la Universidad de Castilla-La Mancha. Recuperado de: http://www.cervantesvirtual.com/obra-visor/el-celoso-don-lesmes-comedianueva-en-tres-actos--o/html/ff19d6oa-82b1-11df-acc7o02185ce6064_2.html\#I_o_ 
Viñao Frago, A. (2003). La educación en las obras de Josefa Amar y Borbón. Sarmiento, $7,35-60$.

Cómo referenciar este artículo/How to reference this article:

Martínez López, M., (2021). Los modelos y el papel de las mujeres en la comedia ilustrada. Un caso práctico de su enseñanza y análisis en las aulas universitarias desde el enfoque de género. iQUAL. Revista de Género e lgualdad, 4, 142-160, doi: 10.6018/iqual.433871

Martínez López, M., (2021). Los modelos y el papel de las mujeres en la comedia ilustrada. Un caso práctico de su enseñanza y análisis en las aulas universitarias desde el enfoque de género. [Models and the role of women in illustrated comedy. A practical case of its teaching and analysis in university classrooms from a gender perspective]. iQUAL. Revista de Género e lgualdad, 4, 142-160, doi: 10.6018/iqual. 433871

\section{Anexo I}

El contexto de contenidos dentro del cual se desarrolla el ejemplo docente que voy a desarrollar, es el siguiente

1. Introducción a la comedia neoclásica

1.1. Nacimiento y desarrollo del género

1.2. Rasgos: estructura, tipologías de personajes y temas (educación, hombre de bien/mujer de bien, respeto a la autoridad, fidelidad, importancia del núcleo/gobierno familiar, crítica a la ociosidad y defensa del trabajo, etc...)

1.3. Autores y obras destacados

2. Análisis de La familia a la moda de María Rosa Gálvez

2.1. Semblanza biográfica

2.2. Producción de la autora

2.3. Análisis de la obra: estructura, personajes, características estéticas neoclásicas, temas y rasgos ideológicos ilustrados, etc.

3. Estado de la cuestión: El personaje femenino en otras obras neoclásicas. Argumentos de comedias costumbristas, comedias heroicas y tragedias neoclásicas españolas con protagonistas femeninas. Temas.

3.1. Apuntes para establecer los paradigmas de género femenino y masculino en el teatro

4. La imagen de la mujer en la comedia neoclásica. El papel femenino en otros géneros. Ejemplos.

4.1. La sutil crítica a los matrimonios concertados en la Carta LXXV de José Cadalso (Cartas marruecas)

4.2. La educación y los tres modelos femeninos en Eudoxia, hija de Belisario, de Pedro de Montengón

4.3. Otros ejemplos

5. Otras autoras de la literatura española del siglo XVIII

5.1. Parnaso poético femenino

5.2. Dramaturgas

5.3. Novelistas 
6. La defensa social de la mujer: Carlos III, Josefa Amar y Borbón, Benito Jerónimo Feijoo y Gaspar Melchor de Jovellanos

6.1. Proyectos de promoción de la mujer al amparo de la Sociedad Económica Matritense. La Junta de Damas de Honor y Mérito.

6.2. Las Reales Sociedades de Amigos del País y el reto de la educación de la mujer

6.3. La defensa de las mujeres de Feijoo dentro de su Teatro crítico universal (17261739)

6.4. Las memorias sobre la admisión de mujeres en las Sociedades Económicas por Jovellanos y Josefa Amar (discursos a favor)

6.5. La visión de las mujeres en Josefa Amar

6.6. Otros ejemplos 